\title{
Impact of Electric Vehicles on Power Quality in a Smart Grid Context
}

\author{
Vítor Monteiro, Henrique Gonçalves, João L. Afonso \\ Centro Algoritmi - Departamento de Electrónica Industrial \\ Univ. Minho - Campus de Azurém 4800-058 - Guimarães, Portugal \\ E-mail:vmonteiro@dei.uminho.pt; hgoncalves@dei.uminho.pt; jla@dei.uminho.pt
}

\begin{abstract}
The large dependency of the imported fossil fuels and the soaring oil prices, makes essential the look for alternatives to the traditional people transportation system. The natural bet is the electric mobility, namely Electric Vehicles (EV), and Plug-in Hybrid Electric Vehicles (PHEV). This way, in this paper is analyzed the potential impacts of the battery charging systems on the grid power quality, in a Smart Grid context. It is considered the current consumed, according to a typical electric consumption profile, and the voltage degradation for a large number of houses. Two different types of $\mathrm{EV}$ batteries chargers were considered: a traditional charger; and a smart charger with sinusoidal current consumption and unitary power factor. It presents simulation results of the integration of EVs and PHEVs in terms of power quality, and experimental results of a smart charger which was specially developed for $\mathrm{EV}$ charging and that allows mitigation of the power quality degradation.
\end{abstract}

Keywords: Electric Vehicles, Plug-in Hybrid Vehicles, Smart Charge, Power Quality, Smart Grids

\section{INTRODUCTION}

Nowadays, due to the large dependency of the imported fossil fuels and the soaring oil prices, makes essential the look for alternatives to the traditional people transportation system, mainly support by road vehicles. The alternatives should also limit greenhouse gases as $\mathrm{CO} 2$ in order to reduce global warming and to meet Kyoto restrictions.

A great part of the oil consumption is nowadays allocated to the transportation sector and a large portion is used by road vehicles. According to the international energy outlook report, the transportation sector is going to increase its share in world's total oil consumption by up to $55 \%$ by 2030 [1]. Thus, with the technological development, the natural bet is a revolution in the transportation sector aiming the electric mobility. This could be obtained implementing alternatives to the vehicles with Internal Combustion Engines (ICE), such as Electric Vehicles (EV), Plug-in Hybrid Electric Vehicles (PHEV), and Fuel-Cell Electric Vehicles (FCEV). These alternatives are becoming increasingly popular, as demonstrated with the various vehicles available in the market, mainly EVs (as Nissan Leaf) and PHEVs (as Toyota Prius). These vehicles were designed to allow the charging of the batteries at home, from a standard outlet, or on a public vehicle park. When a vehicle is plugged into the electrical grid, theoretically it is possible to have a bidirectional flux of energy. This interactivity between the EVs and PHEVs, with the electrical grid is expected to be one of the key technologies in the future of the Smart Grids concept. In this context, in [2] is approached the future of the electrical grid focusing the impact of the PHEV in a Smart Grid, and in [3] is presented a concrete case of a technology to integrate EV with Smart Grids. With the large scale integration of renewable energy sources into the electrical grid, the batteries of the EVs and PHEVs can play an important role for smoothing the natural intermittency of the renewable energy sources and to ensure the electrical grid stability in terms of voltage and frequency.

It is known that the EVs battery charging systems affect the electrical distribution system, and that contributing to the degradation of the power quality [4]-[8]. In a report published by the California Energy Commission [7] is presented a study about the impact of the residential electric vehicles charging systems. As example, for the GM EV1 the Total Harmonic Distortion (THD) of the current has a variation from $3 \%$ (at beginning of charging) to $28.11 \%$ (at end of charging). For this vehicle, and to these two periods, the power factor has a variation from 1 to 0.96 . In this report are also presented others results about others EV. Similar study is presented in [9]. In this sense, it is clear that the simultaneous use of a great number of EV chargers on the electrical distribution grid could cause a significant increase in the power quality.

In this paper it is presented the impact of the EV battery chargers on the power quality in a Smart Grid context, mainly the comparison in terms of the variation of the THD. It is done considering the current consumed and the voltage degradation for a large number of houses each one with one $\mathrm{EV}$, considering two different types of EV batteries chargers: a traditional charger; and a smart charger with sinusoidal current consumption and unitary power factor. This paper presents experimental results of a smart charger which was specially developed for EV charging.

\section{SMART GRID: EVS INTEGRATION}

The EVs have a great potential (due to their stored energy in the batteries) to interact with the electrical grid. This interaction in a Smart Grid context encourages the development of different technologies and approaches as Vehicle-to-Grid (V2G).

\section{A. $\quad$ Vehicle-to-Grid}

As defined by Mid-Atlantic Grid Interactive Cars 
Consortium (MAGICC) [10], V2G technology utilizes the stored energy in the EV batteries to contribute with electricity back to the grid when the grid operators request it. This technology makes an interaction between vehicles and grid, in order to control the needs of both.

\section{B. Power Quality}

Basically, the power quality is affected by the non-linear current consumption of some loads, i.e. the THD of this current. The main problems in power quality are: harmonics; noise (electromagnetic interference); inter-harmonics; momentary interruption; sag; swell; flicker; notches; and transients. As way to resolve these problems are used active power filters as: Shunt Active Power Filters; Series Active Power Filters; and Unified Power Quality Conditioner. In literature several papers already were presented related with the power quality and the grid.

In the particular case of Portugal, in [11] is analyzed the impact of PHEVs in the electric utility system, where, basically is approached the Portuguese consumption profile. Several scenarios of PHEVs penetration are studied considering the concept Grid-for-Vehicle (G4V) (transference of energy from grid to vehicle) as first approach. The impacts of battery charging rates of EVs on Smart Grid distribution systems are approached in [12]. For this goal were compared charging rates, different charging periods along a day, were considered the existing system load profiles, and was evaluated the overall performance of the electrical distribution system. The integration of EVs in the electrical grid is approached in several papers in the literature [13]-[15], as the integration of PHEVs in different part around the world, as in Canada [16], Sweden [17], and China [18]. In this context, also for isolated systems, in [19] is analyzed the impact of the EVs in the electrical power grid.

\section{C. $\quad$ Charging Process}

The charging or discharging process of the batteries of the EVs can be realized in two different shapes: coordinated or uncoordinated.

Coordinated Charging: with this profile, the batteries of the EVs are charged or discharged according the capabilities of the electrical grid in real time and the needs of the vehicle owner. In this context different parameters are taken into account, mainly the price of energy to sell or buy and the remaining energy stored in the batteries, their State-of-Charge (SoC). In [20] is proposed an autonomous distributed vehicleto-grid control scheme, and in [21] is presented a coordinated charging of multiple PHEVs in residential distribution grids. The integration of EVs in the electrical grid, describing technical solutions is present in [22].

Uncoordinated Charging: from the moment which the vehicle is plugged into the electrical grid the charging can starts immediately or after a fixed time delay (controlled by the user). With this uncoordinated charging the power consumption (due to the large number of EV to charge) will be great and will bring problems to the electrical grid. The discharging of the batteries directly to the electrical power grid is made without the performances of the coordinated charging.
This is the most common charge procedure. As presented in [23] for the Portuguese case, in medium term, the smart charge will be necessary in order to prevent a large peak of energy demand from the electrical power grid.

\section{Battery Charger Especifications}

Independently the shape, the EV charging process can be on-board, off-board, conductive or inductive. An on-board charging system refers to a charger implemented inside the vehicle. The user only accesses the input of the charge. This charger is used to charge the bank of batteries slowly, denominated slow charge (AC voltage). On other hand, an offboard charger system is implemented out of the vehicle, and access directly the bank of batteries (DC voltage). Contrarily of the on-board charger, this is used to charge the batteries as fast as possible, denominated fast charge. The conductive charge presupposes a physical contact between the off-board chargers, instead, with the inductive charger there are not a physical contact between both. Independently of the charger type, the interaction between the EVs and PHEVs with the electrical grid should comply with the norms. The main norms presented by the International Electrotechnical Commission (IEC) are IEC 62196 and IEC 61851

\section{EV BATTERY CHARGER DESIGN}

EVs are becoming a part of the electric grid day by day, and consequently, the chargers for these vehicles have the ability to make this interaction better for the consumer and for the electrical grid. An EV battery charger is a device that is composed of one or more power electronics circuits used to convert the AC electrical energy into DC with an appropriate voltage level in order to charge the batteries. It has the potential to increase charging availability of the EVs since it can operate as a universal converter accepting different voltage and power levels. An advanced charger performs several functions in addition to the charging operation for better grid integration, mainly taking into account the power quality. Independently the level of the charging, to the integration of the EVs in a Smart Grid context aiming the power quality, the chargers should consume sinusoidal current with unitary power factor. In Fig. 1 is presented the EV batteries charger developed. This charger consumes sinusoidal current with unitary power factor, has fewer components when compared to more complex topologies, and allow operate in two different ways: as charger or discharger.

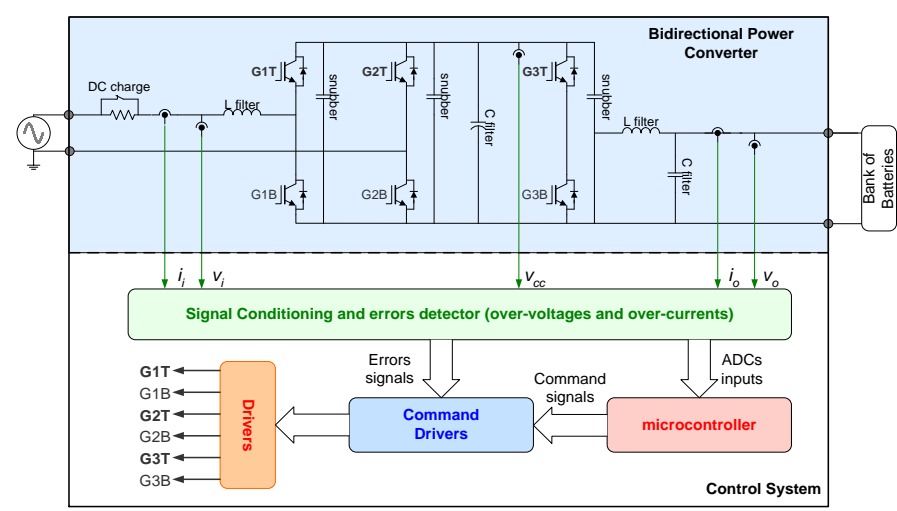

Figure 1. Topology of the EVs charger. 
As illustrated this converter is composed by two main parts: the bidirectional power converter (composed by the inductances, capacitors, and IGBTs); and the control system (composed by the microcontroller DSP, the signal conditioning, the command drivers and the drivers).

\section{Simulation Methodology}

In this item is described the potential impacts of EV and PHEV on the electrical grid, including a typical electric consumption profile, focusing the power quality, mainly the system voltage and the consumed current. Thus, for all the simulations were considering fifteen houses, each one with different loads profiles, including an EV which may have a traditional charger or a smart charger. In a traditional batteries charger the current consumed is distorted and the power factor is near the unit, meaning a high value of THD. Otherwise, in a smart batteries charger, the current consumed is sinusoidal and the power factor is unitary, representing a small value of THD.

In this scenario, the simulation methodology aims determine how the EVs batteries chargers affect the power quality, taking into account these fifteen houses and the line impedance. Due to the houses are connected to the same distribution transformer, other parameter analyzed is the voltage, both in the distribution transformer as in the last house (house that is more distant from the distribution transformer). This is a parameter which cannot be despised, because although in the houses near from the distribution transformer the voltage is little affected, due to the line impedance between houses, the voltage in the house more distant will be affected, which represent an increase in their THD, and consequently, can cause problems of malfunctioning to the others loads of this house. This representation is in Fig. 2.

\section{SimUlation RESUltS}

In order to analyze the behavior of the EV in the electrical grid, mainly their impact in terms of power quality, were made different simulations using the simulation tool PSIM. In these simulations were included the traditional loads present in most homes, as well as their profiles of consumption current. These loads are summarized in the Tab. I.

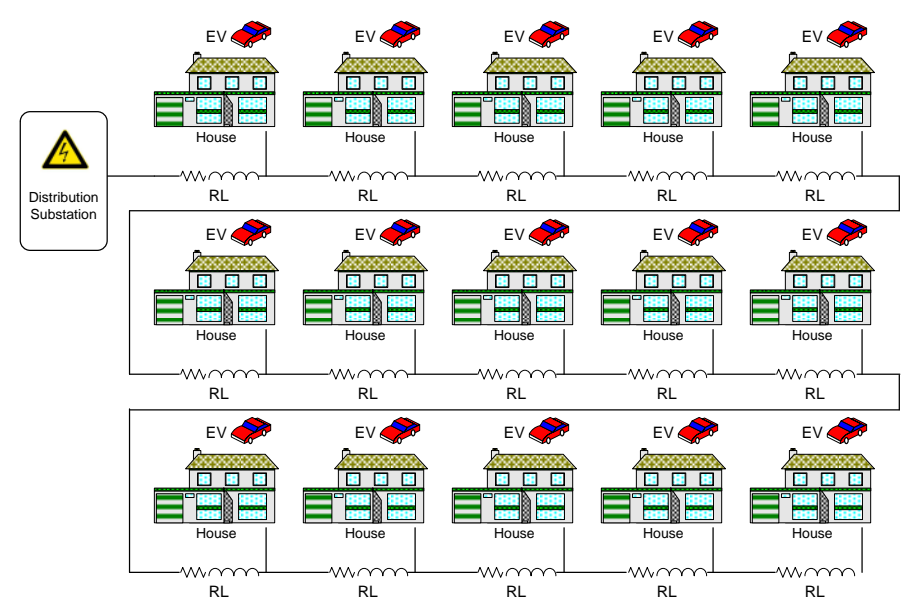

Figure 2. Simulation methodology: all houses with EVs.
TABLE I. TRAditional LoAdS PRESENT In Most Homes

\begin{tabular}{|c|c|c|c|c|c|}
\hline Symbol & Description & $\begin{array}{c}\text { Voltage and } \\
\text { Current } \\
\end{array}$ & $\begin{array}{c}\text { Power } \\
\text { (W) }\end{array}$ & $\begin{array}{r}\text { THD } \\
\text { v }(\%)\end{array}$ & $\begin{array}{l}\text { THD } \\
\text { i }(\%)\end{array}$ \\
\hline $\begin{array}{l}\sqrt{44} \\
+4 \\
4\end{array}$ & $\begin{array}{c}\text { bridge } \\
\text { rectifier } \\
\text { with } \mathrm{C} \text { filter }\end{array}$ & & 30 & 0.12 & 150 \\
\hline & RL load & & 110 & 0.01 & 0.37 \\
\hline & $\mathrm{R}$ load & & 527 & 0.01 & 0.01 \\
\hline & $\begin{array}{l}\text { AC-AC } \\
\text { converter }\end{array}$ & & 258 & 0.31 & 20.7 \\
\hline
\end{tabular}

A. Single House

In this item, in Fig. 3 are presented the current consumed for a single house with all the loads connected to the electrical grid, for the following situations: (1) a house without EV; (2) a house with a traditional EV charger (without sinusoidal waveform current consumption); and (3) a house with a smart EV charger (with sinusoidal waveform current consumption). In Tab. II are summarized the obtained values of THD and RMS of the voltage and current. For this simulation when the EV with a traditional charger is in charging, the increase of THD is $79.6 \%$. Otherwise, if the EV has a smart charger the THD is reduced to $2.9 \%$. Due to the high current consumed when compared with the other loads, the integration of the EV with a smart charger will improve the power quality.

\section{B. $\quad$ Neighborhood (all houses only with EVs)}

In Fig. 4 are shown the current consumed (when the only loads are the EVs) and the voltage in the last house for the following situations: (1) a house with a traditional EV charger; and (2) a house with a smart EV. In Tab. III are summarized the THD and the RMS values of the voltage and the current. As presented, for this simulation (only with the EVs of all houses), the difference of THD from both simulations is $74.3 \%$. This difference of THD is abrupt and represents a determinant factor of power quality. In addition, as shown the voltage THD in the last house is very affect by the THD of the current consumed when the EV charger is the traditional $(7.3 \%)$. Otherwise, if the EV has a smart charger, the THD of the voltage more reduced $(3.3 \%)$. If consider more houses, the voltage THD in the last house will be more affected, representing other serious problem of power quality.

\section{Neighborhood (all houses with all loads)}

In this item, in Fig. 5 are presented the distribution system voltage and the current consumed by the neighborhood with all the loads connected to the electrical grid, for the following situations: (1) all houses with a traditional EV charger; (2) all houses with $60 \%$ of the EV smart charger; and (3) all houses with a smart EV charger. In Tab. IV are summarized the obtained values of THD and RMS of the voltages and the current consumed. As shown the voltage THD in the electrical grid is more affected when the EVs have a traditional charger. To the same point in the electrical grid the difference of the voltage THD is $1.8 \%$. On the other hand, the current consumed THD is reduced from $51.6 \%$ to $1.8 \%$, representing a $49.8 \%$ gain. 

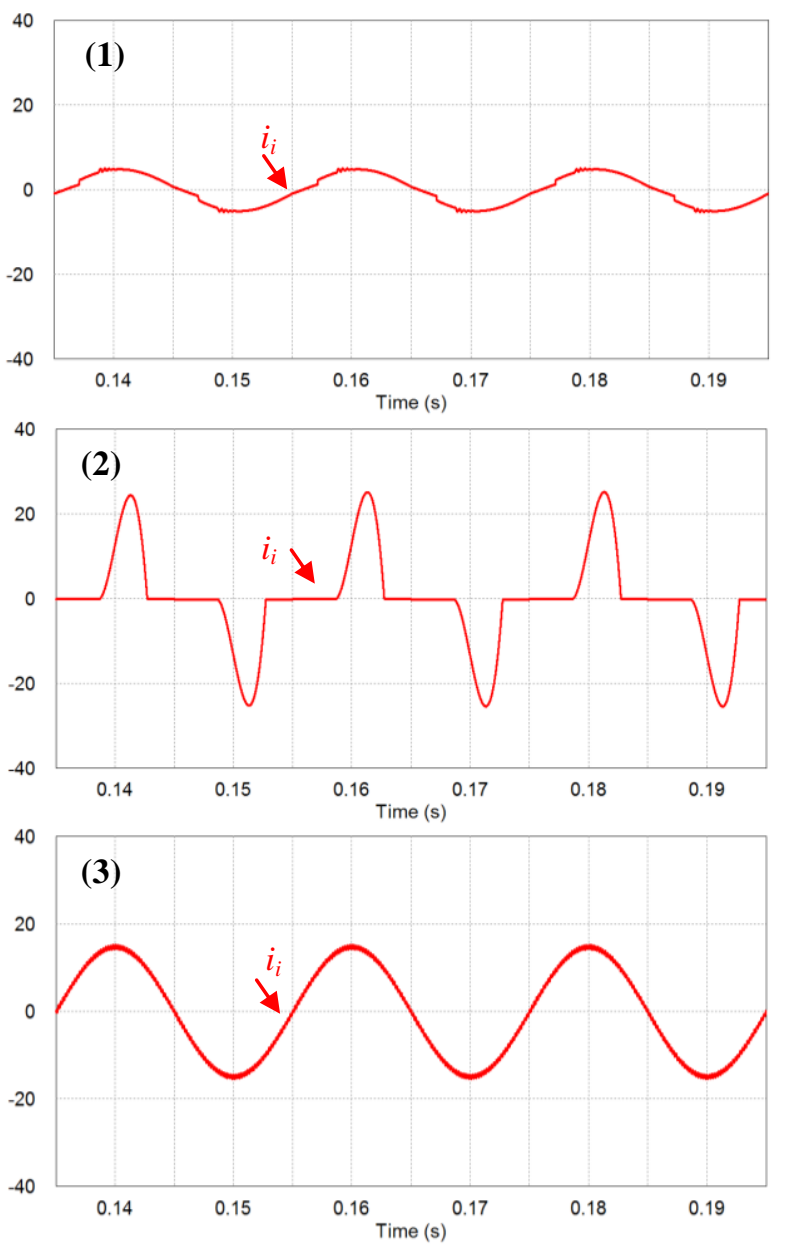

Figure 3. Current consumed for a single house with all the loads connected to the electrical grid: (1) a house without EV; (2) a house with a traditional EV charger; (3) a house with a smart EV charger.
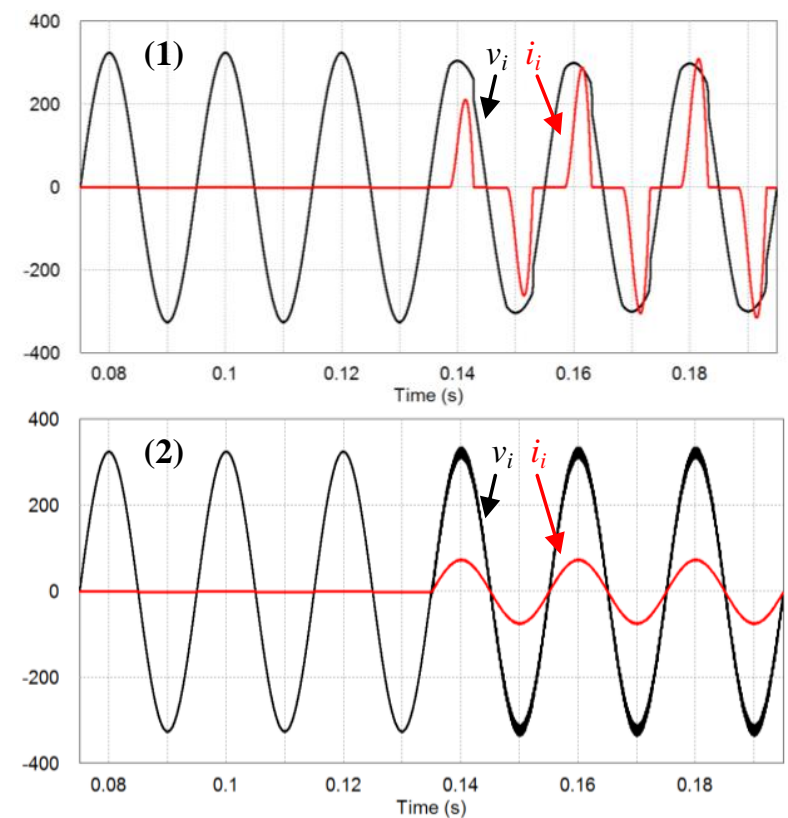

Figure 4. Current consumed and voltage in the last house: (1) a house with a traditional EV charger; (2) a house with a smart EV charger.
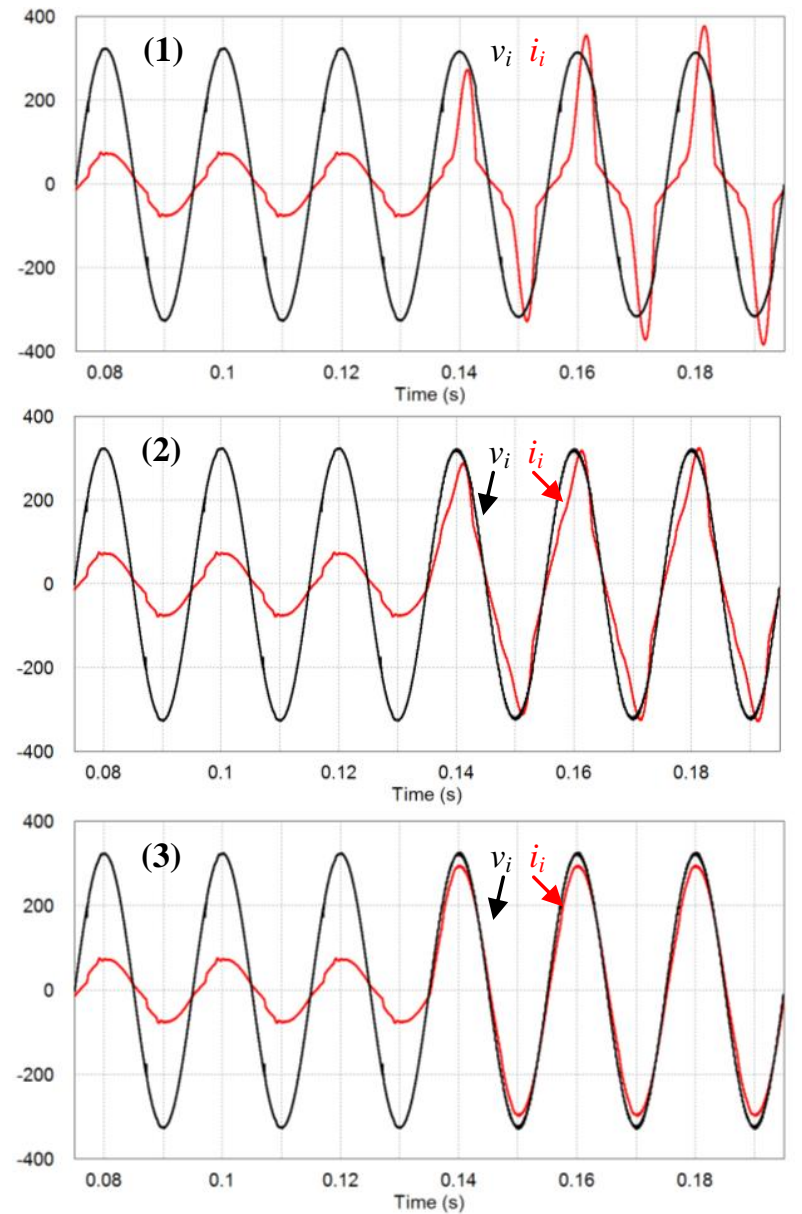

Figure 5. Distribution system voltage and current consumed with all the loads connected to the electrical grid: (1) all houses with a traditional EV charger; (2) all houses with $60 \%$ of the EV smart charger; (3) all houses with a smart EV charger.

TABLE II. THD AND RMS VALUES OF THE VOLTAGE AND CURRENT

\begin{tabular}{|c|c|c|c|}
\hline & \multicolumn{3}{|c|}{ current $\left(\boldsymbol{i}_{\boldsymbol{i}}\right)$} \\
\cline { 2 - 4 } & $\mathbf{( 1 )}$ & $\mathbf{( 2 )}$ & $\mathbf{( 3 )}$ \\
\hline THD (\%) & 7.67 & 87.3 & 2.86 \\
\hline RMS & $3.50(\mathrm{~A})$ & $10.7(\mathrm{~A})$ & $10.5(\mathrm{~A})$ \\
\hline
\end{tabular}

TABLE III. THD AND RMS VALUES OF THE VOLTAGE AND CURRENT

\begin{tabular}{|c|c|c|c|c|}
\hline \multirow{2}{*}{} & \multicolumn{2}{|c|}{$(\mathbf{1})$} & \multicolumn{2}{c|}{$(\mathbf{2})$} \\
\cline { 2 - 5 } & voltage $\left(\boldsymbol{v}_{\boldsymbol{i}}\right)$ & current $\left(\boldsymbol{i}_{\boldsymbol{i}}\right)$ & voltage $\left(\boldsymbol{v}_{\boldsymbol{i}}\right)$ & current $\left(\boldsymbol{i}_{\boldsymbol{i}}\right)$ \\
\hline THD $(\%)$ & 7.28 & 75.2 & 3.30 & 0.95 \\
\hline RMS & $228(\mathrm{~V})$ & $90.2(\mathrm{~A})$ & $229(\mathrm{~V})$ & $111(\mathrm{~A})$ \\
\hline
\end{tabular}

TABLE IV. THD and RMS VALUES OF THE VOLTAGE AND CURRENT

\begin{tabular}{|c|c|c|c|c|}
\hline \multirow{2}{*}{} & \multicolumn{2}{|c|}{ before } & \multicolumn{2}{c|}{ after } \\
\cline { 2 - 5 } & voltage $\left(\boldsymbol{v}_{\boldsymbol{i}}\right)$ & current $\left(\boldsymbol{i}_{\boldsymbol{i}}\right)$ & voltage $\left(\boldsymbol{v}_{\boldsymbol{i}}\right)$ & current $\left(\boldsymbol{i}_{\boldsymbol{i}}\right)$ \\
\cline { 2 - 5 } & \multicolumn{4}{|c|}{$(\mathbf{1})$} \\
\hline THD (\%) & 0.40 & 7.66 & 2.87 & 51.6 \\
\hline RMS & $230(\mathrm{~V})$ & $52.3(\mathrm{~A})$ & $228(\mathrm{~V})$ & $168(\mathrm{~A})$ \\
\hline & \multicolumn{5}{|c|}{$(\mathbf{2})$} \\
\hline THD (\%) & 0.40 & 7.66 & 1.62 & 19.5 \\
\hline RMS & $230(\mathrm{~V})$ & $52.3(\mathrm{~A})$ & $229(\mathrm{~V})$ & 188 \\
\hline & \multicolumn{5}{|c|}{$(\mathbf{3})$} \\
\hline THD $(\%)$ & 0.40 & 7.66 & 1.06 & 1.82 \\
\hline RMS & $230(\mathrm{~V})$ & $52.3(\mathrm{~A})$ & $229(\mathrm{~V})$ & $207(\mathrm{~A})$ \\
\hline
\end{tabular}




\section{PROPOSED CHARGER: EXPERIMENTAL RESUlTS}

A prototype of the charging and discharging system was implemented in laboratory. It consists in two bidirectional power converters, one AC-DC and other DC-DC. In Fig. 6 are shown the IGBTs modules of the power converters (with drivers and snubber capacitors), mounted in the same heatsink.

In Fig. 7 is shown the voltage $\left(v_{i}\right)$, the current $\left(i_{i}\right)$ and the current reference $\left(i_{r e f}\right)$ in the electrical grid side. As shown in this figure until the start-up (made at $\mathrm{t}=0.018 \mathrm{~s}$ ) the AC-DC converter is not in functioning, and consequently, the current waveform is not sinusoidal. From the start-up the consumed current waveform is sinusoidal and in phase with the voltage, without any kind of transitory disturbance. From this moment the voltage in the DC bus increases. As shown in Fig. 8, in steady state, the consumed current $\left(i_{i}\right)$ is sinusoidal and in phase with the voltage $\left(v_{i}\right)$. In Fig. 9 is showed the voltage in electrical grid side $\left(v_{i}\right)$, the current consumed $\left(i_{i}\right)$, the voltage in the DC bus $\left(v_{c c}\right)$, the voltage in the bank of batteries $\left(v_{o}\right)$, and the current consumed by the bank of batteries $\left(i_{o}\right)$. On the other hand, in Fig. 10 is shown the obtained results to the voltage $\left(v_{i}\right)$ and to the current $\left(i_{i}\right)$ in the electrical grid side during the delivering of the stored energy of the bank of batteries to the electrical grid. As shown, the injected current is sinusoidal and phase opposition with the voltage.

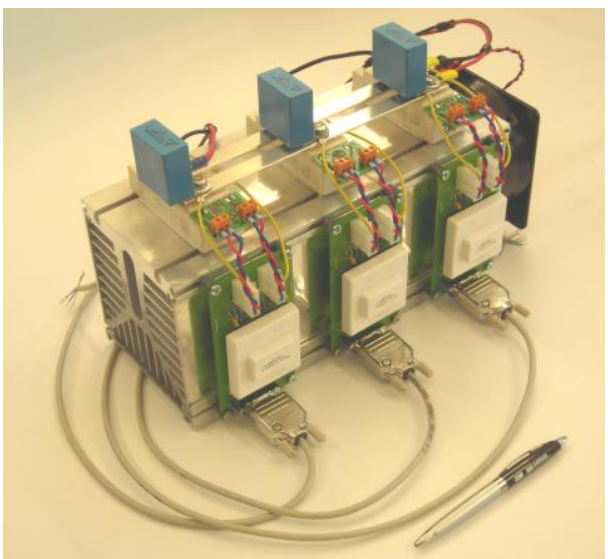

Figure 6. AC-DC and DC-DC IGBTs modules of the power converters.

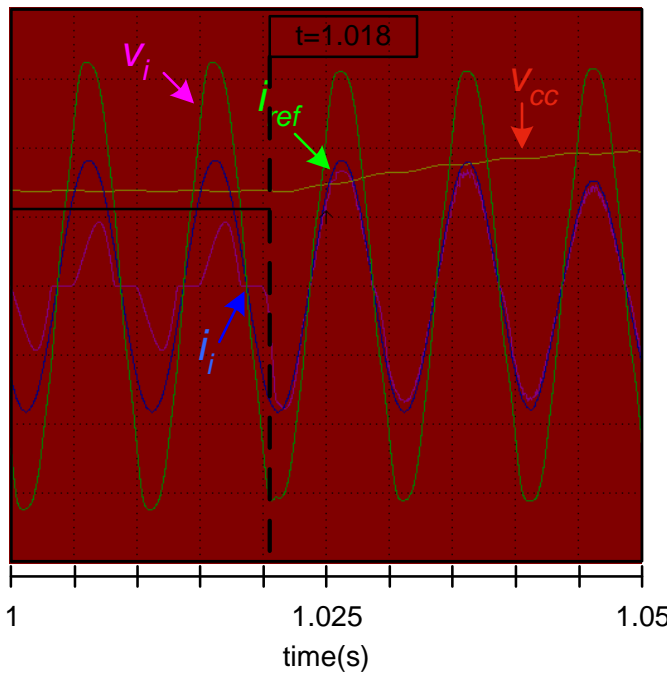

Figure 7. Experimental results: start-up of the EV smart charger.

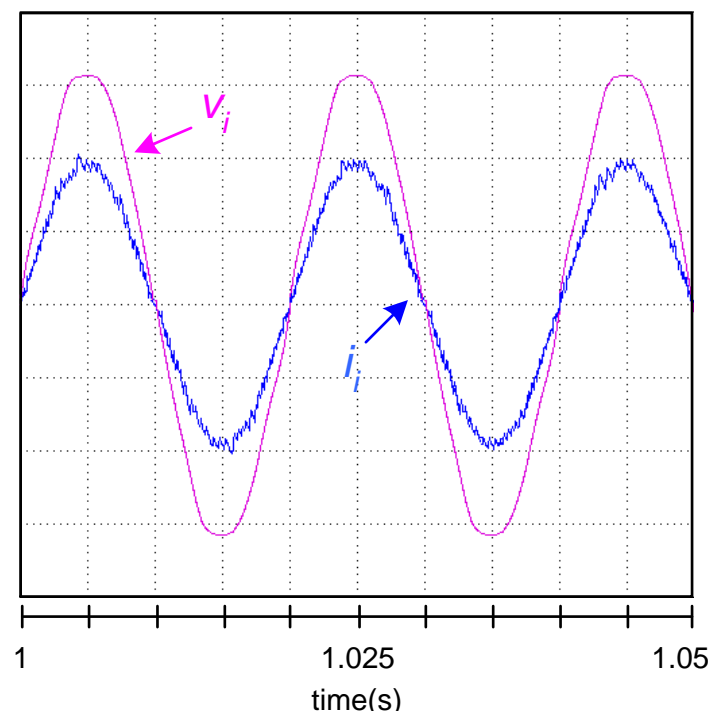

Figure 8. Experimental results: current and voltage in phase during charging.

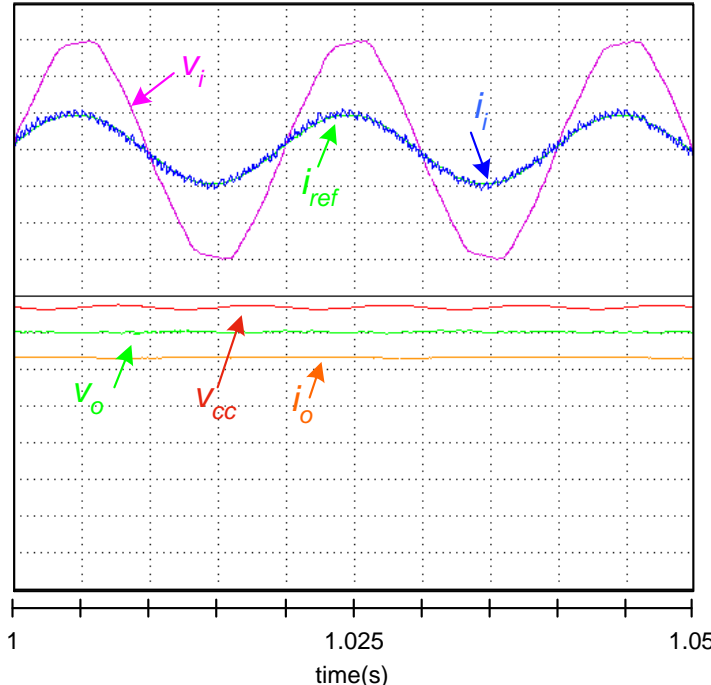

Figure 9. Experimental results: current and voltage in phase during charging.

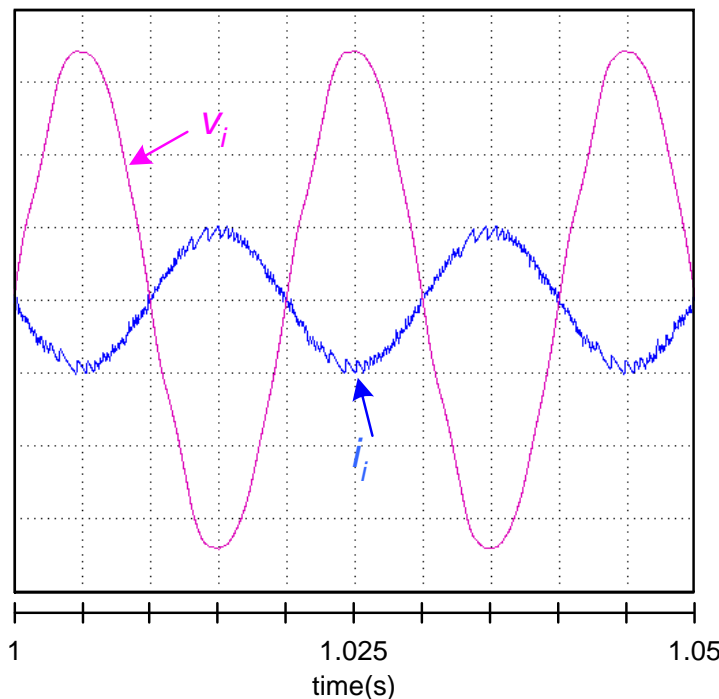

Figure 10. Experimental results: current and voltage in phase during discharging. 


\section{CONCLUSION}

In this paper was analyzed the potential impacts of the Electric Vehicles (EV) and Plug-in Hybrid Electric Vehicles (PHEV) on the electrical power grid, including the typical residential profile of electrical consumption. Thus, was explored the new EV paradigm aiming their integration in the electrical power grid - Vehicle-to-Grid (V2G), focusing the power quality associated with this integration, mainly the system voltage and the consumed current profiles. In this paper is illustrated how the EV integration affect the power quality, where we can conclude which if the vehicle charger consume sinusoidal current waveform with unitary power factor, the THD of the total current in the electrical grid is drastically reduced, and the voltage is not affected.

For the case example shown, with all the loads connected to the electrical grid, the current consumed THD is reduced from $51.6 \%$ (traditional EV charger) to $1.8 \%$ (smart charger). On the other hand, for the same example, the voltage in the last house (house that is more distant from the distribution transformer) is affected by a $7.3 \%$ voltage drop, which can cause problems of malfunctioning to the others loads of this house.

Also in this paper, it was presented a battery charger for EV that allows mitigates the power quality degradation. Along the batteries charging cycle, this charger consumes sinusoidal current with unitary power factor, and allows control the voltage and current in the batteries in order to maximize the batteries lifespan. Beyond the charging, this system allows discharge a small part of the stored energy in the batteries back to the electrical grid, which can be, in the near future, an interesting solution during short periods of times when occur peaks of energy demand in the electrical system.

\section{ACKNOWLEDGMENT}

This work is financed by FEDER Funds, through the Operational Programme for Competitiveness Factors COMPETE, and by National Funds through FCT Foundation for Science and Technology of Portugal, under the project PTDC/EEA-EEL/104569/2008 and the project MITPT/EDAM-SMS/0030/2008

\section{REFERENCES}

[1] "International Energy Outlook 2009," Energy Information Administration Office of Integrated Analysis and Forecasting U.S. Department of Energy Washington DC, May 2009.

[2] A.Ipakchi, F.Albuyeh, "Grid of the Future," IEEE Power \& Energy Magazine, March/April 2009.

[3] S.S.Hernandez, P.P.Galindo, A.Q.Lopez, "EPV PROJECT. Technology to integrate EV inside smart grids," IEEE 7th International Conference on the European Energy Market (EEM), 2010.

[4] J.C.Gomez, M.M.Morcos, "Impact of EV Battery Chargers on the Powe Quality of Distributed Systems," IEEE Transactions on Power Delivery, Volume:18, Issue:3, pp:975, 2003

[5] P.T.Staats, W.M.Grady, A.Arapostathis, R.S.Thallam, "A Statistical Method for Predicting the Net Harmonic Currents Generated by a Concentration of Electric Vehicle Battery Chargers," IEEE Transactions on Power Delivery, Volume:12, Issue:3, pp.1258-1266, 1997
[6] P.T.Staats, W.M.Grady, A.Arapostathis, R.S.Thallam, "A Procedure for Derating a Substation Transformer in the Presence of Widespread Electric Vehicle Battery Charging," IEEE Transactions on Power Delivery, Volume:12, Issue:4, pp.1562-1568, 1997

[7] Frank Lambert, "Secondary Distribution Impacts of Residential Electric Vehicle Charging," California Energy Commission, May 2000

[8] S.Rahman, G.B.Shrestha, "An Investigation into the Impact of Electric Vehicle Load on the Electric Utility Distribution System," IEEE Transactions on Power Delivery, Volume:8, Issue:2, pp.591-597, 1993.

[9] M.M.Morcos, N.G.Dillman, C.R.Mersman, "Battery Chargers for Electric Vehicles," IEEE Power Engineering Review, Volume:20, Issue:11, pp.8, 2002.

[10] MAGICC - Mid-Atlantic Grid Interactive Cars Consortium (2011, 3 June). MAGICC [Online]. Available: http://www.magicconsortium.org/research_partners.html

[11] C.Camus, C.M.Silva, T.L.Farias, J.Esteves, "Impact of Plug-in Hybrid Electric Vehicles in the Portuguese Electric Utility System," IEEE POWERENG International Conference on Power Engineering, Energy and Electrical Drives, pp.285-290, 2009.

[12] A.S.Masoum, S.Deilami, P.S.Moses, A.Abu-Siada, "Impacts of Battery Charging Rates of Plug-in Electric Vehicle on Smart Grid Distribution Systems," IEEE PES Innovative Smart Grid Technologies Conference Europe, pp.1-6, 2010.

[13] S.Shao, M.Pipattanasomporn, S.Rahman, "Challenges of PHEV Penetration to the Residential Distribution network,"IEEE PES Power \& Energy Society General Meeting, pp.1-8, 2009.

[14] J.A.P.Lopes, F.J.Soares, P.M.R.Almeida, "Integration of Electric Vehicles in the Electric Power System," Proceedings of the IEEE, Volume:99, Issue:1, pp.168-183, 2011.

[15] L.Zhao, S.Prousch, M.Hubner, A.Moser, "Simulation Methods for Assessing Electric Vehicle Impact on Distribution Grids," IEEE PES Transmission and Distribution Conference and Exposition, pp.1-7, 2010.

[16] G.Joos, M.R.Dubois, "Integration of PHEVs and EVs Experience from Canada," IEEE PES Power and Energy Society General Meeting, pp.1-5, 2010

[17] L.Bertling, O.Carlson, S.Lundmark, D.Steen, "Integration of plug in hybrid electric vehicles and electric vehicles - experience from Sweden," IEEE PES Power and Energy Society General Meeting, pp.1-3, 2010.

[18] Y.Song, X.Yang, Z.Lu, "Integration of Plug-in Hybrid and Electric Vehicles Experience from China," IEEE PES Power and Energy Society General Meeting, pp.1-6, 2010.

[19] P.Kadurek, C.Ioakimidis, P.Ferrao, "Electric Vehicles and their Impact to the Electric Grid in isolated systems," IEEE POWERENG Power Engineering, Energy and Electrical Drives, pp.49-54, 2009.

[20] Y.Ota, H.Taniguchi, T.Nakajima, K.M.Liyanage, J.Baba, A.Yokoyama, "Autonomous Distributed V2G (Vehicle-to-Grid) considering Charging Request and Battery Condition," IEEE PES Innovative Smart Grid Technologies Conference Europe (ISGT Europe), pp.1-6, 2010

[21] K.Clement, E.Haesen, J.Driesen, "Coordinated Charging of Multiple PHEV in Residential Distribution Grids," IEEE PES Power Systems Conference and Exposition, pp.1-7, 2009.

[22] R.J.Rei, F.J.Soares, P.M.R.Almeida, J.A.Pecas Lopes, "Grid Interactive Charging Control for Plug-in Electric Vehicles," 13th International IEEE Conference on Intelligent Transportation Systems, pp.386-391, 2010.

[23] R.Freire, J.Delgado, J.M.Santos, A.T.Almeida, "Integration of Renewable Energy Generation with EV Charging Strategies to Optimize Grid Load Balancing," 13th International IEEE Conference on Intelligent Transportation Systems, pp. 392-396, 2010.

[24] J.Sousa, P.Santos, "MyTracking: Sistema de Tracking de Movimentos de Condutores de Veículos em modo 'off-line'," ISEL - Instituto Superior de Engenharia de Lisboa, PFC - Projecto Final de Curso, 2010.

[25] C.Russo, N.Bento, "V2G Smart System," ISEL - Instituto Superior de Engenharia de Lisboa, PFC - Projecto Final de Curso, 2010. 